\title{
Healthier Parents - Effects of Parent Training Programs on Mental Health
}

\author{
Hans O. Löfgren ${ }^{1, *}$, Mojgan Padyab ${ }^{2}$, Mehdi Ghazinour ${ }^{3}$, Karin Nilsson ${ }^{1}$, \\ Solveig Petersen ${ }^{1,}$, Bruno Hägglöf ${ }^{1}$ \\ ${ }^{1}$ Child and Adolescent Psychiatry, Department of Clinical Sciences, Umeå University, Sweden \\ ${ }^{2}$ Department of Social Work, Umeå University, Sweden \\ ${ }^{3}$ Police Academy, Umeå University, Sweden \\ ${ }^{4}$ Epidemiology and Global Health, Department of Public Health, Umeå University, Sweden
}

\begin{abstract}
The study aims to investigate the effects of Parent Training Programs on the mental health of parents with children aged between 1 and 17 in a universal preventive setting. The intervention group included 279 parents who were assigned to five professionally administered interventions, which included 5-10 two-hour sessions; they were then compared to 702 parents in the comparison group without intervention. The improvement in general mental health was statistically significant in the intervention group compared to the comparison group. The findings suggest that evidence-based parent training programs enhance well-being in parents without indicated problems. However further exploration of preventive training programs for parents are needed.
\end{abstract}

Keywords Parental Training Program, Universal Interventions, General Mental Health, GHQ

\section{Introduction}

This study investigated the extent to which parental training programs can affect parents' mental health, if there is any effect. The World Health Organization (WHO) definition of mental health is a state of well-being in which every individual realizes his or her own potential, can cope with the normal stresses of life, can work productively and fruitfully, and is able to make a contribution to her or his community (WHO, 2017). Parental mental health is important during child development (Knoche, Givens, \& Sheridan, 2007). Parents with higher levels of depression who initially used more health and social care services and participated in parenting programs showed reduced levels of parental depression as well as reduced overall health and social service usage; however, this only applied in programs where parents participated without their children (Charles, Bywater, Edwards, Hutchings, \& Zou, 2013), and it only applied in longitudinal studies (Jensen et al., 2014).
Parenting is the ability of parents to adjust their behavior to the developmental needs of a child, thereby ensuring children's health and safety, and eventually to adjust their behavior in phase with children's maturation to prepare them for life as productive adults. Successful parenting is based on parental feelings for children, and not on intelligence or intellectual capability (APA, 2000; Winnicott, 1971). Parents are ordinarily the most consistent and caring people in the lives of children (Bornstein, 2001). Warm feelings and beneficial responsiveness toward the child creates a core of stability during the child's development, regardless of changes brought about by cognitive and socio-emotional developmental acquisitions (Ainsworth, 1979). The converse, unresponsive parents that are unaroused and inattentive to the point of neglect or angrily aroused and excessively attentive to detail that they attack the child, can create attachment problems that harm the child's development (Ainsworth, Blehar, Waters, \& Wall, 2014) and result in dissatisfaction with life in adulthood (Overbeek, Stattin, Vermulst, Ha, \& Engels, 2007). A good-enough attachment is hard to attain if there is no sense of competence in the parental role. A parent's sense of competence has been linked to personality and parental skills (de Haan, Prinzie, \& Dekovic, 2009; Pisterman et al., 1992).

Studies support the use of parenting programs to improve the short-term psychosocial well-being of parents (Barlow, Smailagic, Huband, Roloff, \& Bennett, 2014) and also to improve parents' health (Punamäki, Paavonen, Toikka, \& Solantaus, 2013; Sanford et al., 2003). A number of meta-studies provide evidence that programs intended for selective prevention do contribute to, or strengthen, good parenting as well as improving moderately harmful or ineffective parenting (Barlow et al., 2014; Furlong et al., 2012; Kaminski, Valle, Filene, \& Boyle, 2008; Olsson, Hagekull, \& Bremberg, 2003). Those meta-studies indicate that targeting parents' attitudes, skills and consistency are important aspects of successful outcomes in parental programs (Prinzie et al., 2012). Moreover, in Sweden, a number of studies have evaluated the effect of parental 
training programs (Forster, Kling, \& Sundell, 2012; Hallberg \& Håkansson, 2003; Thorell, 2009). From an international perspective, Scandinavia has good childhood conditions (Heshmati, Bajalan, \& Tausch, 2007). However, despite good health and a good child and adolescent health-care system in Sweden, the situation could be better; maltreatment and child abuse has increased over the last decade, while the number of crimes solved has declined (BRA, 2016). In addition, school surveys and studies report an increase in mental health problems among adolescents in Sweden, especially among girls (Bremberg, 2004; Carlerby, Viitasara, Knutsson, \& Gillander Gadin, 2011; Hutton, Nyholm, Nygren, \& Svedberg, 2014; Swedish National Institute of Public Health, 2014; The National Board of Health and Welfare, 2009). The quality of parental care (and peer relationships) in adolescence predicts adult mental and functional somatic health as much as 26 years later, even when accounting for confounders and adolescent symptomatology (Landstedt, Hammarström, \& Winefield, 2015). To support families, The National Board of Health and Welfare stated that a parenting program should be provided to parents in the governmental bill, "Support in parenting" (Danielsson, 1997). That statement of intent culminated in the report "New tools for parents" (Bremberg, 2004). With the increasing pace of the development of methods of parenting programs, there is a need to evaluate and study the effectiveness of these various programs. Few studies have evaluated the effects of universal preventive programs on parental mental health. The authors searched Google Scholar, PubMed and Web of Science for studies published in the last 20 years with the key words universal, preventive, parent/al, training, management, program/s , programme/s (minus, school, cancer, tobacco, alcohol, new-born, hearing, media); and found no study that had intervention groups that participated in a parent training program included in the current study. However, six studies (Cann, Rogers, \& Matthews, 2003; Hiscock et al., 2008; Kendall, Bloomfield, Appleton, \& Kitaoka, 2013; Geoff Lindsay \& Strand, 2013; Neville et al., 2013; Zubrick et al., 2005 ) investigated the effect of similar programs. However, the three studies by Zubrick, Hiscock and Neville et al. each took place within a socioeconomically deprived region, and were associated with significant reductions in parent-reported levels of dysfunctional parenting (Zubrick et al.) and stress (Neville et al.). The authors have confirmed Cann's study $(\mathrm{N}=589)$ as being truly universal and found a significant decrease in scores on the Depression, Anxiety, Stress Scale (DASS) from pre- to post-intervention $(\mathrm{F}=46.1, \mathrm{p}<0.001)$. In addition the DASS score for 49 parents changed from pre-clinical to post-non-clinical, and it changed for 19 parents from pre-non-clinical to post-clinical (chi2 $=12.4$ ) in the depression subscale. Lindsay's study showed an increase in positive parent mental well-being $(\mathrm{N}=431)$, with an effect size of 0.85 . In Kendall's study $(\mathrm{N}=49)$ the parental distress change was not statistically significant $(\mathrm{p}=0.39)$, likewise in Hiscock's study $(\mathrm{N}=291, \mathrm{p}=0.09)$. In Sweden, two studies were found (Alfredsson \& Broberg, 2016; Ulfsdotter, Enebrink, \& Lindberg, 2014), where the intervention group participated in a parent training program (Comet and $\mathrm{ABC}$ ) that is not included in the current study. In Alfredsson's study, the intervention participants consisted of mothers than fathers, more single mothers than not single mothers, and more mothers with higher education levels than the average population in Sweden. Fathers were more frequently out of work than in the average population. Mothers, fathers and children had more psychosocial difficulties than the average population at pre-score. No effect was reported; instead Alfredsson and Broberg studied the parents' reasons for enrolment and concluded that the universal approach does seem to reach its intended recipients. In Ulfsdotter's study, the intervention group showed a beneficial increase in self-efficacy and better mental health for the children. Having poor positive mental health, a university-level education, more than one child in the family, and older children, resulted in greater benefit to the families. The following investigation might contribute to already-existing knowledge by studying the effect of universal preventive programs among parents.

\section{Aim}

The study aims to investigate the effect of parental training programs on parents' mental health in the general population in a naturalistic setting.

\section{Method}

\section{Ethical Considerations}

The Regional Ethical Review Board in Umeå approved the study, with reference number 2010/249-31Ö, and the study followed the APA Ethics Code. The research team offered psychosocial counseling in the information letter, and this service was provided to one parent in the intervention group. The current study is part of a comprehensive study on parental competence.

\section{Participants}

Participating parents were self-selected and recruited through a broad advertisement about the project. To provide information about the study, a variety of communication methods were used: advertisements in local newspapers, flyers, a website, and personal visits to schools and kindergartens from public relations staff. In total, 5,655 families were invited to participate in the current study. According to other studies (Lindsay, Strand, \& Davis, 2011), a drop-out rate was calculated for the comparison group and so the authors ordered 5,000 addresses for 
families, randomly selected from a government database, chosen according to the same distribution curve of the children's ages in the intervention group. This resulted in 4,997 addresses (three were incorrect). In the intervention group, 658 parents were invited, including 28 couples, who signed up to participate in the parental training programs. They represent at least one parent from $3.3 \%$ of all families with children in the region $(\mathrm{N}=16,329$ April 2010).

In the intervention group, of 658 invited families, $215 \mathrm{did}$ not respond and nine parents were excluded for the following reasons: one child turned 18 during the study period; four parents had another child in focus in postmeasures, hereafter referred to as the "focus child"; four parents were disqualified due to conflict of interest and some form of connection to the study. A further 155 were lost to follow-up between pre- and post-intervention, leaving an intervention group of 279 parents.

In the comparison group, 103 parents were excluded for the same reasons as the intervention group, and 385 were lost to follow-up, leaving a sample of 709 parents in the comparison group.

\section{Procedures}

A web-based questionnaire was used and disseminated for use on tablets. The questionnaire was designed using the Questback Webb application. Responses to the web-questionnaires were collected at the first meeting of the parental training program (pre-test), and directly after the last meeting (post-test). In case a researcher or parent could not be present, the pre- and/or post-test link to the questionnaire was remotely sent by e-mail. The comparison group completed an identical paper version of the questionnaire at home. Data collections from the intervention group took place between September 2010 and May 2013. Data collection from the comparison group took place between June and September 2013.

\section{Interventions}

Aktivt Föräldraskap (Active Parenting-AP) had 113 participants (44\% of the intervention group) in different locations in the county of Västerbotten. Active Parenting is the first manual-based interactive program to use video recordings in Sweden. AP was developed by Michael Popkin and is based on Adler's development theory on learning (Allen, El-beshti, \& Guin, 2014).

The Community Parent Education Program (COPE) had 51 participants $(20 \%)$. This program, which has Canadian origins, is a manual-based education program using video recordings and small-group problem-solving discussions. The program is based on social learning theory, social cognitive psychology and family system theory (Cunningham, Bremner, \& Boyle, 1995). COPE was validated as an effective parental training program for reducing problems such as conduct, hyperactivity, impulsiveness, parental stress and daily problems, but not for reducing peer problems, social skill deficits or inattention (Thorell, 2009).

Familjeverkstan (Family Workshop) had 35 participants (14\%). The Family Workshop was developed by the Centre of Prevention for Stockholm City and is a manual-based communication program using video recordings, which targets parents of children aged between 3 and 12. It has been stated that discussions are less guided than in other parental training programs, although it is based on the same theories and clinical experience (Forster 2008).

Family-Lab, Dialog Based Parenting, had 36 participants (14\%), of whom 23 were in Gothenburg parental training groups. The founder, Jesper Juul, based the program theory on his experience of family therapy in Scandinavia. The program is dominated by dialog enhancement between the responsible parent and the competent child (Schill, 2013).

Älskade Förbannade Tonåring (I Love You, But You Drive Me Nuts) had 44 participants (17\%). This parental training program is a Swedish "circle of self-study" organized by community educational associations. It aims to contribute to a better dialog between parents and their teenagers, along with providing advice about how to guide teenagers in different situations. The method is based on the Iowa Strengthening Families Program (Spoth, Redmond, Trudeau, \& Shin, 2002), while the program itself is based on a Swedish book (Kimber \& Molgaard, 2009) and is a focus for group discussions guided by a "circle leader", along with homework and practical tasks.

All leaders in the parental training programs have completed the education requirements for each program, which was confirmed by the organization responsible for each program.

\section{Measures}

\section{Sociodemographic Variables}

Parent age was a continuous variable (years). Gender had two categories, male and female. Marital status was a dichotomous variable, married or cohabiting versus single. Number of children in the family was a dichotomous variable, one child versus more. Parent education was a dichotomous variable, less than 12 years of education (below high school) versus more than 12 years of education (above high school). Child and parent origin of birth was a dichotomous variable depending on whether or not they were born in Sweden. Work status was indicated by full-time versus not full-time. In addition, the age and gender of the focus child were included in the sociodemographic questionnaire.

\section{GHQ-12}

Detection of mental illness has been a major challenge for health care. In 1972, the General Health Questionnaire (GHQ) was developed by Goldberg as a self-administered screening test to detect probable mental illness in general health-care settings (Goldberg, 1972). GHQ consists of questions asking whether the respondent has recently, in 
terms of weeks, experienced a particular symptom, such as "Have you recently lost much sleep because of worries?", or behavior, such as "Have you recently been able to face up to your problems?". In this study, the 12-item version was used. The items are rated on a four-point Likert-scale (Banks et al., 1980) compared with respondents' "usual state of mind". The options are 0 (no more than usual); 1 (same as usual); 2 (more than usual) and 3 (much more than usual). A higher score indicates more mental health problems. Likert-scoring gives a minimum score of zero and a maximum of 36 . The Likert-scale was used in this study, according to Banks' (1980) recommendation that the "Likert-method might be preferable in that it is likely to produce a wider and less skewed distribution of scores more appropriate for correlational analyses and intergroup comparisons based on parametric statistics". In general, it is best if the user specifies their required threshold value, based on research evidence relevant to their assessment circumstances. However, no clinical assessments or gold standard are available to compare with the scores; therefore, with some precaution, threshold values of $11 / 12$ points from earlier studies were used as default options (Goldberg, Oldehinkel, \& Ormel, 1998; Mayou \& Hawton, 1986). Banks et al. reported a Cronbach's alpha value between .82 and .90 .

\section{Additional Questions}

Other than the questions about the instrument and demographic, additional questions about the family were added. In the post-test the following question was added: "Has a major incident occurred, which had a big effect on your family, since you started parental training (e.g., a change in work status or financial circumstances, or a death)? Please specify." Parents were also asked whether the parent "had more trouble concerning the focus child than what they consider to be normal. (Yes/No)". There was an open question inviting free comment about the parental program. For the comparison group the question was "Has a major incident occurred, which had a big effect on your family, since you started this survey (e.g., a change in work status or financial circumstances, or a death)? Please specify." Finally, there were three additional questions about the focus child. In the pre-test, the first question was whether the parent "has had any trouble with the child, other than s/he considers to be normal". The second question asked whether the child "had experienced any physical problems other than s/he considers to be normal". The third question asked whether the child "had experienced any psychological problems other than s/he considers to be normal".

\section{Statistical Analysis}

Univariate descriptive statistics were used to describe the sample. The authors applied bi-variate analyses, including t-test and chi-square, to examine the difference between continuous and categorical independent variables, respectively, between the intervention and comparison groups. To compare pre-post-intervention differences, the paired t-test was used. In addition to the comparison of preand post-test intervention scores, a calculation of the change was added, which is a comparison of the mean change between the measurement points (T2-T1). An interventiontime interaction analysis was applied to assess the intervention effect at $\mathrm{T} 2$. Simple linear regression was used to assess the correlation between changes in post-intervention and baseline (pre-intervention) scores. Cohen's effect-size measure was used to quantify the change between the pre- and post-tests between the two groups, in which 0.2 is defined as a "small" effect size, 0.5 as a "medium" effect size, and 0.8 as a "large" effect size (Cohen, 1988). Cronbach's alpha coefficient was applied to assess the internal consistency of the GHQ questionnaire. Other internal consistency assessment methods were used, which included the item-remainder correlation coefficient (the correlation of the item score with the composite score that excludes the item from the equation), with an acceptable value between 0.5 and 0.7 (Ferketich, 1991). The number of participants may differ in the tables presented herein because of missing values. To deal with missing value bias, DeSouza's protocol (DeSouza, Legedza, \& Sankoh, 2009) was followed using expectation-maximization in 19 cases. All analyses were performed in SPSS version 24 (SPSS, Released 2017) and a p-value $<0.05$ was set to detect significant changes.

\section{Results}

\section{Sample Characteristics}

The baseline characteristics of the study participants and the comparison between intervention and comparison groups are presented in Table 1. No statistical difference was found for child age and parent age between the intervention and comparison groups (Table 1). There were more boys in the intervention group compared with the comparison group (57.4\% vs. $48.3 \%$, respectively, $\mathrm{p}<0.01)$. There were more male parents in the intervention group compared with the comparison group (20.1\% vs. $12.5 \%$, respectively, $\mathrm{p}<0.01)$. No statistical difference was found regarding the number of children, origin of children, origin of parents and parent education. The proportion of single parents was significantly higher in the intervention group compared with the comparison group (16.4\% vs. $7.3 \%$, respectively, $\mathrm{p}<0.01$, Table 1$)$. There were more parents with full employment in the intervention group (81.4\% vs. $70.9 \%$, respectively, $\mathrm{p}<0.01$ ). 
Table 1. Demographic variables at baseline

\begin{tabular}{|l|l|c|c|}
\hline & & $\begin{array}{l}\text { Intervention group } \\
(\mathrm{n}=279)\end{array}$ & $\begin{array}{l}\text { Comparison group } \\
\text { \% or Mean (SD) }\end{array}$ \\
\% or Mean (SD)
\end{tabular}

Drop-out analysis in the intervention group was carried out with a statistically significant difference between the drop-out group $(\mathrm{n}=155)$, compared to remaining respondents $(\mathrm{n}=279)$; regarding parents' gender (more male parents), older children, and parent's origin (more fathers born outside of Sweden). There was no difference between the drop-out group and the remaining group for the other variables, including e-mail or paper questionnaire, physical or psychological health. The pre-test GHQ score \pm standard deviation for the drop-outs was higher compared to the remaining parents $(12.68 \pm 6.20 \mathrm{Vs}, 11.36 \pm 5.60$, respectively, $\mathrm{p}<0.05$ ).

Internal consistency was studied by considering Cronbach's alpha for the GHQ questionnaire. In the current study, Cronbach's alpha was 0.89 in the whole sample, 0.90 among the intervention group and 0.88 among the comparison group. There were no internal negative correlations within the items, and all items resulted in a negligible change in Cronbach's alpha if items were deleted. The item-remainder correlations ranged between 0.48 and
0.71 in the current study, suggesting acceptable values.

\section{Comparison Between Intervention and Comparison Groups}

The dependent variable was the change between the preand post-test means of the GHQ. The mean GHQ pre-score in the whole sample was $9.6 \pm 5$. The mean and standard deviation of GHQ scores before and after intervention are presented in Table 2. In the intervention group, the mean GHQ score \pm Sd before the intervention was $11.25 \pm 5.58$, indicating that the general mental health status of parents who sought parental training groups was slightly above the threshold of 11 points for probable mental illness. The post-intervention mean GHQ score decreased by 1.74 score points, that is, $9.51 \pm 4.93$ in the intervention group, which is below the threshold of 11 points. Of 106 parents who were above the threshold, nearly half (59 parents) dropped below the threshold after the intervention. Conversely, of 173 parents whose scores were lower than the threshold, $18 \%$ (32 parents) moved above the threshold at post-test. 
One-third responded with confirmation to the question "Has a major incident occurred, which had a big effect on your family?" and were found to be above zero line in the upper side in figure 2.

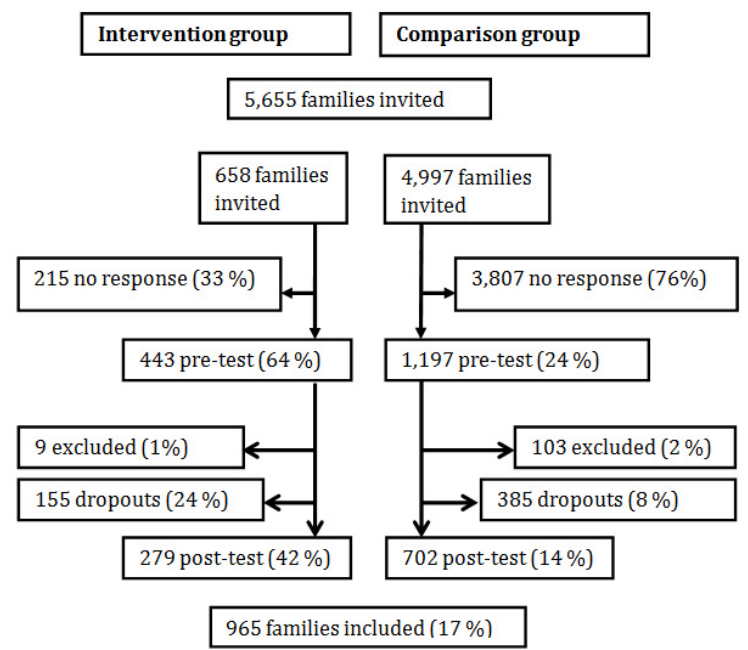

Figure 1. Flow chart of participation

There was no statistically significant mean change in the comparison group between pre-test $(8.93 \pm 4.58)$ and post-test $(8.93 \pm 4.6)$ (Table 2$)$.

The mean difference between the measurement points was -1.74 and the pooled standard deviation was 5.40 points. The raw effect size was medium, 0.32, in favor of the intervention group. The results from linear regression, in which the change score is the dependent variable and the pre-score is the independent variable, showed that the pre-intervention score explains $33 \%$ of the variability of the change in GHQ score $\left(\mathrm{R}^{2}=0.33\right)$ and one unit increase in pre-score corresponds to a 0.61 decrease in change score (change score $=5.32-0.61 \times$ pre-score). The break-even point was 8.72 where the group mean pre-score did not predict any increase in GHQ in the regression model. Of those parents in the comparison group, who were over the threshold of 11 points $(n=136), 51$ dropped below the threshold. At first, the overall change was measured separately within the groups by t-value, without controlling for any confounding variables.

The intervention-time interaction analysis (time effect) showed significant intervention effects $(F=19.0, p<0.001$,
Table 2).

\section{Differences Between Parental Groups}

As shown in figure 2, the difference between the intervention and comparison groups is clear. There is a small within difference between two of the programs where some of the parents' symptoms actually increased. The qualitative data in the written comments provide a clue to problems within relationship. Examples of open comments highlighted as a major incidence include: "Relationship problems between the parents". Open comment: "I have reflected a lot over my actions and relation to her [the child], but even more so over my husband. This has created a cliff between us, a lot of conflicts and an absence of consensus. Unfortunately."

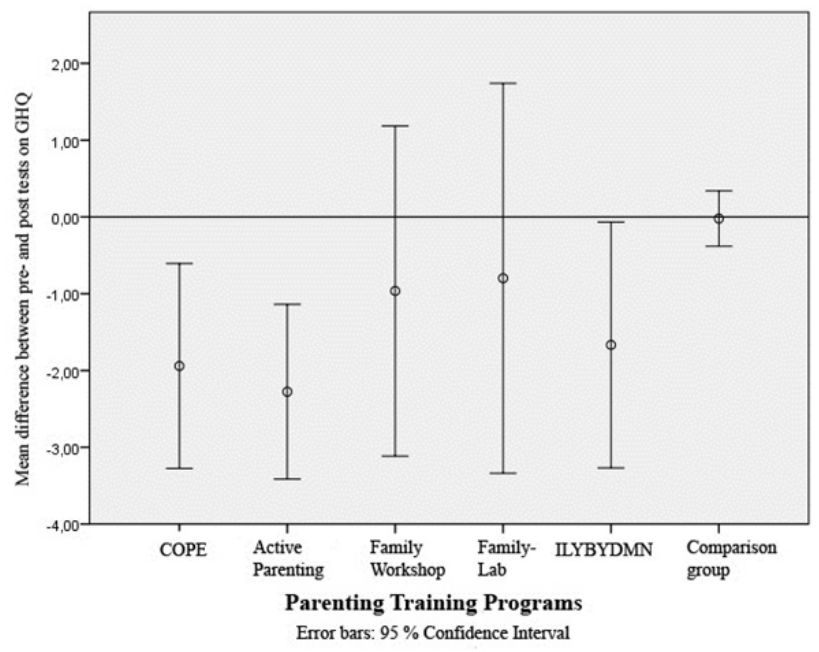

*ILYBYDMN = I Love You But You Drive Me Nuts program

Figure 2. Differences between the parental training groups.

Significant differences were found between the intervention group and the comparison group in terms of experiencing more trouble with children $(24.8 \%$ vs. $6.8 \%$, respectively, $\left.\chi^{2}=64.92, \mathrm{p}<0.001\right)$, child psychological problems ( $15.3 \%$ vs. $5.4 \%$, respectively, $\chi^{2}=26.47, \mathrm{p}<$ $0.001)$ and child physical problems $(6.6 \%$ vs. $14 \%$, respectively, $\left.\chi^{2}=10.83, \mathrm{p}<0.001\right)$.

Table 2. Comparison of GHO scores at pre- and post-intervention among study participants

\begin{tabular}{|l|c|c|l|l|l|}
\hline \multirow{2}{*}{ GHQ score } & $\mathrm{T}_{1}$ & \multicolumn{1}{c}{$\mathrm{T}_{2}$} & $\begin{array}{l}\text { Comparison of pre- and } \\
\text { post- intervention scores }\end{array}$ & Change $\mathrm{T}_{2}-\mathrm{T}_{1}$ & $\begin{array}{l}\text { Interaction between } \\
\text { Intervention } \\
\text { and Time }\left(\mathrm{T}_{1} \text { vs. } \mathrm{T}_{2}\right)\end{array}$ \\
\cline { 2 - 6 } & Mean (SD) & Mean (SD) & & Mean (SD) & \\
\hline & & & & $-1.74(5.97)$ & $\mathrm{F}=19.0, \mathrm{p}<0.001$ \\
\hline Intervention & $11.25(5.58)$ & $9.51(4.93)$ & $p<0.001$ & $0.004(4.85)$ & \\
\hline Comparison & $8.93(4.58)$ & $8.93(4.60)$ & $p=0.98$ &
\end{tabular}




\section{Discussion}

The current study examined the effects on parents' perceptions of their mental health. It took place in a municipal setting with limited possibilities to implement a well-controlled research design. For instance, there were many different stakeholders and different agendas, and response rate was also a problem. Even if the authors had reached the entire target population, it would not be possible to know whether the whole spectrum of the target population was represented. The possibility of systematic bias cannot be excluded, as noted in other studies (Lindsay et al., 2011). However, this research provided an opportunity to study the reality of parental training programs being implemented in the general population. The results showed that parental training programs have a positive influence on parents' own view of their mental well-being, with a medium effect size of 0.32 . This result cannot be explained by time, cultural circumstances (Shriver \& Allen, 2008), or changes in society (e.g. family political decisions, increased gross domestic product, or social media influences), due to the lack of similar changes in the comparison group. One of the more interesting findings was that the intervention group had mean pre-scores above the threshold of 11 points of the GHQ-12, but post-scores dropped below the threshold, while the comparison group had scores below the threshold in both pre- and post-scores. A possible explanation for this finding could be that the improvement in parental mental health was a side-effect of parent training by providing parents with tools to better manage family stress. A less likely explanation is that parents in the intervention group sought parent training as a direct way to improve their mental health. This result adds to the somewhat contradictory reports of other studies on parental training. Mullin, Quigley, and Glanville (1994) reported significant change scores favoring the intervention group, $\mathrm{p}<.001$ compared to the control group, $p=.81$. Patterson and colleagues (2002) reported no significant difference between the two groups (CI: - .55 - .26). Both the aforementioned studies also used GHQ. It is worth noting that the current study's intervention group had a higher pre-score than both Mullins (6.62), and Patterson (4.30). However, in the current study, the intervention group did not reach the mean of the comparison group, even after participation. The mean scores prove that parents in need do seek preventive help, and often get better. There were a few respondents who showed a negative outcome, an increased score for mental health problems, and one-third reported spousal problems. Calculating a break-even point provides 8.72 on the GHQ scale at pre-test; over that score shows that the chance of improvement increases at group level. A small (positive) change for a vast amount of the population, in any field of concern, will change the average score, and therefore move the normal distribution curve in a (positive) direction and have a large effect in reducing the total number of negative outcomes in the tail of the distribution curve in the field of concern (Dretzke et al., 2005; Sarkadi, Sampaio, Kelly, \& Feldman, 2014). This is called the preventive paradox (Rose, 2008), which leads to the possibility that enhanced parental well-being, even to a small extent, in the majority will lead to fewer families with problems in the tail of normal distribution.

An ongoing debate in Sweden - concerning unethical discipline methods used by parents - has infiltrated the parental training programs. The issue concerns the parent using warmth and affection as a pay-off for the child's good behavior and using isolation, "time-out" or ignoring, as punishment for bad behavior. Opponents of this approach point out that this is a negative behavioristic psychological approach, and that it does not support a relationship-based attachment between the parent and child (Gustavsson 2009). The debate reached a turning point in 2009 when the Swedish National Institute of Public Health declared that time-out is a suitable approach when a parent takes a child away from a stressful situation without leaving the child alone, but it is not appropriate to isolate the child alone in a different room. Ignoration can be appropriate when the child repeatedly asks for something inappropriate, despite the parent answering clearly. But ignoration is not appropriate in terms of ignoring the child as a person, as in ostracism. There is a clear tendency that all five parental training programs in the current study are responsive to this critique and claim to have abandoned "time-outs", replacing them instead with open discussion about upbringing.

The strengths of the current study comprised good-enough cooperation with all stakeholders in the municipal setting, which easily could hamper or destroy a study. There was a successful test of time-saving response technology, which was appreciated by the parents, where it was possible to avoid typing and categorization errors. It was a strength that the chosen instrument of measure was accurate and gave significant results, because improvements in parental mental health are difficult to measure if well-being is very high in the pre-test, even if extreme results in the pre-test provided less extreme result in the post-test, as in regression toward the mean. Another strength was that the actual parental training programs were suited for preventive use, in the same way as the instruments. Only the parental training method COPE had previous findings of positive effects in the control sample compared to the clinical sample (Thorell, 2009). Most parental training programs in Sweden are developed for use for indicated purpose and have little or no readjustment toward a preventive purpose.

\section{Conclusions}

Conclusions from this study are that parents benefit from parent training programs. Programs fulfill a function and enhance parental mental health. Further investigations need to be confirmed in studies with more restricted designs. 


\section{Acknowledgments}

This study was funded by the Swedish National Institute of Public Health (grant numbers HF $\AA 2009 / 192$ (NKC2009/20) and HF $2010 / 95$ (NKC2010/44)). The authors would like to thank all the leaders and participating parents who willingly contributed to the collected data. They would also like to thank Lena Grundberg for assistance in data collection.

\section{REFERENCES}

Ainsworth, M. S. (1979). Infant-mother attachment. American Psychologist, 34(10), 932.

https://doi.org/10.1037/0003-066X.34.10.932

Ainsworth, M. S., Blehar, M., Waters, E., \& Wall, S. (2014). Patterns of attachment: A psychological study of the strange situation. New York: Psychology Press.

Alfredsson, E. K., \& Broberg, A. G. (2016). Universal parent support groups for parents of adolescents: Which parents participate and why? Scand J Psychol, 57(2), 177-184. https://doi.org/10.1111/sjop.12278

Allen, K., El-beshti, R., \& Guin, A. (2014). An integrative Adlerian approach to creating a teen parenting program. The Journal of Individual Psychology, 70(1), 6-20.

APA. (2000). Encyclopedia of psychology. In A. E. Kazdin (Ed.), Encyclopedia of psychology (Vol. Institutions and Environments: Family, School, and Work, pp. 4128). Washington, DC: American Psychological Association.

Banks, M. H., Clegg, C. W., Jackson, P. R., Kemp, N. J., Stafford, E. M., \& Wall, T. D. (1980). The use of the General Health Questionnaire as an indicator of mental health in occupational studies. Journal of Occupational Psychology, 53(3), 187-194. https://doi.org/10.1111/j.2044-8325.1980.tb00024.x

Barlow, J., Smailagic, N., Huband, N., Roloff, V., \& Bennett, C. (2014). Group-based parent training programmes for improving parental psychosocial health. Cochrane Database Syst Rev, 5, CD002020. https://doi.org/10.1002/14651858.CD002020.pub4

Bornstein, M. H. (2001). Parenting: Science and practice. Parenting, 1(1-2), 1-4.

BRÅ. (2016). The Swedish National Council for Crime Prevention (2016 ed.). www.bra.se: Centre for research and development under the Ministry of Justice.

Bremberg, S. R. (2004). New tools for parents - suggestions to new forms of parental support. Sandviken, Sweden.

Cann, W., Rogers, H., \& Matthews, J. (2003). Family Intervention Services program evaluation: A brief report on initial outcomes for families. Australian e-Journal for the Advancement of Mental Health, 2(3), 208-215.

Carlerby, H., Viitasara, E., Knutsson, A., \& Gillander Gadin, K. (2011). Subjective health complaints among boys and girls in the Swedish HBSC study: Focussing on parental foreign background. Int J Public Health, 56(5), 457-464.

https://doi.org/10.1007/s00038-011-0246-8
Charles, J. M., Bywater, T. J., Edwards, R. T., Hutchings, J., \& Zou, L. (2013). Parental depression and child conduct problems: Evaluation of parental service use and associated costs after attending the Incredible Years Basic Parenting Programme. BMC Health Serv Res, 13(1), 523. doi: 10.1186/1472-6963-13-523

Cohen, J. (1988). Statistical power analysis for the behavioral sciences. New York: Psychology Press.

Cunningham, C. E., Bremner, R., \& Boyle, M. (1995). Large group community-based parenting programs for families of preschoolers at risk for disruptive behaviour disorders: Utilization, cost effectiveness, and outcome. Journal of Child Psychology and Psychiatry, 36(7), 1141-1159.

Danielsson, T. (1997). Support in parenthood. Stockholm: Online available from

http://www.regeringen.se/content/1/c6/02/51/00/57b6375f.pdf.

de Haan, A. D., Prinzie, P., \& Dekovic, M. (2009). Mothers' and fathers' personality and parenting: The mediating role of sense of competence. Developmental Psychology, 45(6), 1695-1707. https://doi.org/10.1037/a0016121

DeSouza, C. M., Legedza, A. T., \& Sankoh, A. J. (2009). An overview of practical approaches for handling missing data in clinical trials. J Biopharm Stat, 19(6), 1055-1073. doi: $10.1080 / 10543400903242795$

Dretzke, J., Frew, E., Davenport, C., Barlow, J., Stewart-Brown, S. L., Sandercock, J., Taylor, R. (2005). The effectiveness and cost-effectiveness of parent training/education programmes for the treatment of conduct disorder, including oppositional defiant disorder, in children. Health Technology Assessment, 9(50), 1-250. https://doi.org/10.3310/hta9500

Ferketich, S. (1991). Focus on psychometrics. Aspects of item analysis. Research in Nursing \& Health, 14(2), 165-168. https://doi.org/10.1002/nur.4770140211

Forster, M., Kling, Å., \& Sundell, K. (2012). Clinical significance of parent training for children with conduct problems. International Journal of Conflict and Violence, 6(2), 187-200.

Forster, M. (2008) Bakgrund till Föräldraverkstan. (Background to Family workshop) Statens Folkhälsoinstitut \& Precens Stockholms stad. Online available from https://www.halmstad.se/d ownload/18.7eaaf024126b190abb380002408/1452500105898/bak grund-till-familjeverkstan.pdf.

Furlong, M., McGilloway, S., Bywater, T., Hutchings, J., Smith, S. M., \& Donnelly, M. (2012). Behavioural and cognitive-behavioural group-based parenting programmes for early-onset conduct problems in children aged 3 to 12 years. Cochrane Database Syst Rev, 2, CD008225. https://doi.org/10.1002/14651858.CD008225.pub2

Goldberg, D. (1972). The detection of psychiatric illness by questionnaire: A technique for the identification and assessment of non-psychotic psychiatric illness. Oxford. England: Oxford University Press.

Goldberg, D., Oldehinkel, T., \& Ormel, J. (1998). Why GHQ threshold varies from one place to another. Psychological Medicine, 28(04), 915-921.

https://doi.org/10.1017/S0033291798006874

Gustavsson, L.H. (2009) Timeout som metod i barnuppfostran.(Timeout as a method of nurturing) Online available from

https://larsh.files.wordpress.com/2009/02/timeout-som-metod-i-ba rnuppfostran.pdf 
Hallberg, A. C., \& Håkansson, A. (2003). Training programme for parents of teenagers: Active parental participation in development and implementation. Journal of Child Health Care, 7(1), 7-16.

Heshmati, A., Bajalan, C. S., \& Tausch, A. (2007). Measurement and analysis of child well-being in middle and high income countries, IZA. Discussion Papers, No. 3203, http://hdl.handle.net/10419/34778.

Hiscock, H., Bayer, J. K., Price, A., Ukoumunne, O. C., Rogers, S., \& Wake, M. (2008). Universal parenting programme to prevent early childhood behavioural problems: Cluster randomised trial. BMJ, 336(7639), 318-321. doi: 10.1136/bmj.39451.609676.AE

Hutton, K., Nyholm, M., Nygren, J. M., \& Svedberg, P. (2014). Self-rated mental health and socio-economic background: A study of adolescents in Sweden. BMC Public Health, 14(1), 394.

Jensen, M. R., Wong, J. J., Gonzales, N. A., Dumka, L. E., Millsap, R., \& Coxe, S. (2014). Long-term effects of a universal family intervention: Mediation through parent-adolescent conflict. J Clin Child Adolesc Psychol, 43(3), 415-427.

doi:10.1080/15374416.2014.891228

Kaminski, J. W., Valle, L. A., Filene, J. H., \& Boyle, C. L. (2008). A meta-analytic review of components associated with parent training program effectiveness. Journal of Abnormal Child Psychology, 36(4), 567-589. doi: 10.1007/s10802-007-9201-9

Kendall, S., Bloomfield, L., Appleton, J., \& Kitaoka, K. (2013). Efficacy of a group-based parenting program on stress and self-efficacy among Japanese mothers: A quasi-experimental study. Nursing \& Health Sciences, 15(4), 454-460.

Kimber, B., \& Molgaard, V. (2009). Älskade förbannade tonåring (I Love You, But You Drive Me Nuts). Stockholm: Natur \& Kultur.

Knoche, L. L., Givens, J. E., \& Sheridan, S. M. (2007). Risk and protective factors for children of adolescents: Maternal depression and parental sense of competence. Journal of Child and Family Studies, 16(5), 684-695.

https://doi.org/10.1007/s10826-006-9116-z

Landstedt, E., Hammarström, A., \& Winefield, H. (2015). How well do parental and peer relationships in adolescence predict health in adulthood? Scandinavian Journal of Public Health, 1403494815576360 .

Lindsay, G., \& Strand, S. (2013). Evaluation of the national roll-out of parenting programmes across England: The parenting early intervention programme (PEIP). BMC Public Health, 13(1), 1-32. doi: 10.1186/1471-2458-13-972

Lindsay, G., Strand, S., \& Davis, H. (2011). A comparison of the effectiveness of three parenting programmes in improving parenting skills, parent mental-well being and children's behaviour when implemented on a large scale in community settings in 18 English local authorities: The parenting early intervention pathfinder (PEIP). BMC Public Health, 11, 962. https://doi.org/10.1186/1471-2458-11-962

Mayou, R., \& Hawton, K. (1986). Psychiatric disorder in the general hospital. The British Journal of Psychiatry, 149(2), 172190.

Mullin, E., Quigley, K., \& Glanville, B. (1994). A controlled evaluation of the impact of a parent training programme on child behaviour and mothers' general well-being. Counselling Psychology Quarterly, 7(2), 167-180.

https://doi.org/10.1080/09515079408254143
National Board of Health and Welfare. (2009). Skolans metoder för att förebygga psykisk ohälsa hos barn: en nationell inventering i grundskolor och gymnasieskolor. (School's methods to prevent mental illness in children: a national survey of primary schools and secondary schools) The National Board of Health and Welfare, Published on-line article number 2009-126-174. Online available from

http://www.socialstyrelsen.se/publikationer2009/2009-126-174.

Neville, H. J., Stevens, C., Pakulak, E., Bell, T. A., Fanning, J., Klein, S., \& Isbell, E. (2013). Family-based training program improves brain function, cognition, and behavior in lower socioeconomic status preschoolers. Proceedings of the National Academy of Sciences, 110(29), 12138-12143.

Olsson, I., Hagekull, B., \& Bremberg, S. (2003). Support for parents to promote children's and adolescent mental health. A systematic research review. (2003:20). Stockholm: The Swedish National Institute of Public Health.

Overbeek, G., Stattin, H., Vermulst, A., Ha, T., \& Engels, R. C. (2007). Parent-child relationships, partner relationships, and emotional adjustment: A birth-to-maturity prospective study. Developmental Psychology, 43(2), 429-437. doi: 10.1037/0012-1649.43.2.429

Patterson, J., Barlow, J., Mockford, C., Klimes, I., Pyper, C., \& Stewart-Brown, S. (2002). Improving mental health through parenting programmes: Block randomised controlled trial. Arch Dis Child, 87(6), 472-477. https://doi.org/10.1136/adc.87.6.472

Pisterman, S., Firestone, P., McGrath, P., Goodman, J. T., Webster, I., Mallory, R., \& Coffin, B. (1992). The effects of parent training on parenting stress and sense of competence. Canadian Journal of Behavioural Science/Revue Canadienne des Sciences $d u$ Comportement, 24(1), 41.

Prinzie, P., Deković, M., van den Akker, A. L., de Haan, A. D., Stoltz, S. E. M. J., \& Jolijn Hendriks, A. A. (2012). Fathers' personality and its interaction with children's personality as predictors of perceived parenting behavior six years later. Personality and Individual Differences, 52(2), 183-189. doi: 10.1016/j.paid.2011.10.012

Punamäki, R.-L., Paavonen, J., Toikka, S., \& Solantaus, T. (2013). Effectiveness of preventive family intervention in improving cognitive attributions among children of depressed parents: A randomized study. Journal of Family Psychology, 27(4), 683-690. doi: 10.1037/a0033466

Rose, G. (2008). Rose's strategy of preventive medicine: the complete original text (Vol. 1): Oxford England. Oxford University Press.

Sanford, M., Byrne, C., Williams, S., Atley, S., Ridley, T., Miller, J., \& Allin, H. (2003). A pilot study of a parent-education group for families affected by depression. Canadian Journal of Psychiatry/Revue Canadienne de Psychiatrie, 48(2), 78-86.

Sarkadi, A., Sampaio, F., Kelly, M. P., \& Feldman, I. (2014). A novel approach used outcome distribution curves to estimate the population-level impact of a public health intervention. Journal of Clinical Epidemiology, 67(7), 785-792.

Schill, A. (2013). Om Family-Lab (About Family-Lab) Online available from http://www.family-lab.se/om_family-lab.asp.

Shriver, M. D., \& Allen, K. D. (2008). Cultural issues in parent training: Working with parents of noncompliant children: A guide to evidence-based parent training for practitioners and students, (pp. 139-155). Washington, DC, US: American Psychological Association. 
Spoth, R. L., Redmond, C., Trudeau, L., \& Shin, C. (2002). Longitudinal substance initiation outcomes for a universal preventive intervention combining family and school programs. Psychology of Addictive Behaviors, 16(2), 129.

SPSS. (Released 2017). IBM SPSS Statistics for Windows, Version 24.0. Armonk, NY: IBM Corp.

Swedish National Institute of Public Health. (2014). Health behaviour in school-aged children (HBSC), results from Sweden of the 2013/14 WHO study. Stockholm: Swedish National Institute of Public Health.

Thorell, L. B. (2009). The Community Parent Education Program (COPE): Treatment effects in a clinical and a community-based sample. Clinical Child Psychology and Psychiatry, 14(3), 373-387. https://doi.org/10.1177/1359104509104047
Ulfsdotter, M., Enebrink, P., \& Lindberg, L. (2014). Effectiveness of a universal health-promoting parenting program: A randomized waitlist-controlled trial of all children in focus. BMC Public Health, 14(1), 1.

WHO. (2017). Mental health: a state of well-being. Online available from http://www.who.int/features/factfiles/mental health/en/

Winnicott, D. W. (1971). Playing and reality. London: Tavistock Publications Ltd.

Zubrick, S. R., Ward, K. A., Silburn, S. R., Lawrence, D., Williams, A. A., Blair, E., Sanders, M. R. (2005). Prevention of child behavior problems through universal implementation of a group behavioral family intervention. Prev Sci, 6(4), 287-304. doi: 10.1007/s11121-005-0013-2 